\title{
In search of clusters
}

\author{
Pytrik Altena and Wim Heijman
}

\author{
Wageningen University, Department of Social Sciences
}

\begin{abstract}
The aim of this article is to present the 'regional cluster quick scan' as an efficient and objective tool to scan a region of interest for the presence, nature and development phase of regional clusters. The 'tool' developed in this research is based on the relations between the state of cluster development in regions, competitiveness, and economic growth. First, a theoretical model is developed and then this model is applied to a real case to test the validity of the model. The results indicate the possibility of identifying regional clusters and their competitiveness by using Shift and Share analysis.
\end{abstract}

Keywords: regional clusters, cluster lifecycle competitiveness, economic development, shift and share analysis, quantitative analysis

\section{Introduction}

Since the 1990 publication of "The Competitive Advantage of Nations" by Porter, regional policy practitioners and academic researchers alike have been captivated by the promise of regional development through improved business competitiveness. The book and Porter's later work on competitiveness, innovation and industry clusters contains the premise that regional development can be ensured by the development of regional clusters that improve the competitiveness of a region. Improved competitiveness in turn leads to increased economic growth of the regional economy. The promise of economic growth through cluster development has not only been noticed by academic researchers from a wide ranging field of different sciences. A vast amount of governmental and nongovernmental agencies is concerned with regional clusters to improve regional economies.

Countless qualitative studies have been performed on the formal theory building of regional clusters. These, however, have not led to a concise body of common agreement on cluster theory. Although numerous methods are used to analyse and measure the size and importance of regional clusters, there is no commonly accepted method of cluster determination and measurement (Brown, 2000). By adding quantitative analysis, the concept of clusters and their effect on the regional economy becomes clearer.

The objective of this article is to establish a cost and time efficient objective method to first of all determine the presence of regional clusters; second, to determine the sectors constituting the cluster; and finally to determine the development phase of the clustering of economic activities in regions. Such an objective and efficient tool allows regional development practitioners and academic researchers to identify potential clusters in an effective manner. Furthermore, this method allows for the screening of a region

of interest for potential clusters. The 'regional cluster quick scan,' as designed in this research, is a first screening tool for the presence of regional clusters.

The approach chosen in this research relies on quantitatively established relations between clusters, competitiveness and economic growth.

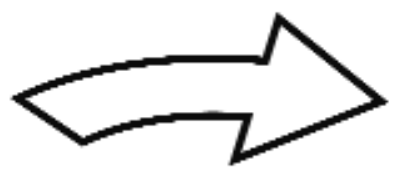

Regional

Clusters
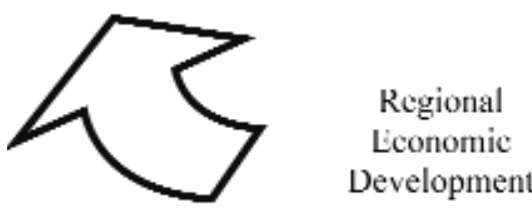

Regional

Competitiveness

Figure 1: Theoretical framework of the regional cluster quick scan

Correlation and regression analyses are performed, for which the causality of clusters leading to competitiveness and competitiveness, which in turn leads to economic growth, is assumed, as this is needed to construct the framework (Figure 1). The most important definitions used in this article are:

\section{Clusters \\ "Clusters are geographic concentrations of} interconnected companies, specialized suppliers, service providers, and associated institutions in a particular field that are present in a nation or a region"

(Porter, 1990). 
Competitiveness:

The degree to which a country can, under free and fair market conditions, produce goods and services which meet the test of international markets, while simultaneously maintaining and expanding the real incomes of its people over the long term" (National Competitiveness Council, 2001).

The strength of clusters is determined by using data provided by the Global Competitiveness Report 2004/2005. To provide an average overview of cluster strength on the national level, an average of the scores was taken and the countries were re-ranked according to this average score. National level data on competitiveness is provided by the same report. Regional level competitiveness on NUTS- 1 level is provided by the Huggins Institute for the year 2004 (Huggins, 2004). National and regional employment data are provided by Eurostat for the European data. In the specific Dutch analyses, data were used from Statline. Data from Eurostat are collected for the years 1999 as the base year and 2004 as the final year of analysis.

\section{Materials and Methods}

Regional clusters: The use of Porter's definition of the concept of regional clusters is a pragmatic choice, which allows for the distinction of two different characteristics of clusters that are, in our opinion, important. The first part of the definition states that clusters are regionally concentrated; the second part indicates that clusters are networks among different participants in the economic process. The first part, the regional co-location of industries, can be quantitatively observed using a wide range of tools available to regional economists (amongst others: location quotients, and Shift and Share analysis as a more dynamic approach and used in this report); uncovering the networks constituting the clusters is still relying on qualitative approaches. The regional cluster quick scan as designed here relies on this regional colocation of industries.

Although the definition does leave much room for discussion on the exact contents of clusters, it is the most widely recognized definition for clusters. The debate on the exact definition for clusters is by no means ended. Martin and Sunley, for example, have catalogued 10 different ways to define the concepts of industry clusters (Cortright, 2006). Cortright suggest a more pragmatic approach among scientists to accept the concept of clusters to be an "umbrella" concept, suitable for relevant policy formulation. By this, he proposes to not exactly define the concept, but rather to look at the commonly shared characteristics of clusters instead.

Theories on clusters: Recently, the most important concepts related to regional clusters have been: labour market pooling, specialized supplier, knowledge spill-overs, entrepreneurship, path dependence and lock in, culture and local demand. (Cortright, 2006). These terms are closely related to both Neo-classical Economy when dealing with labour pooling and scale and scope advantages, primarily in terms of costs of production; and New Economic Growth theory or Endogenous Growth theories. New Economic Growth Theory is a heterodox stream of economics that arose from the 1970s onward, and has challenged Neo-Classical growth models on the assumptions and practical applications. Heterodox theory, like New Growth theory, provides a framework for analysis, pinpointing essential elements of economic activity previously ignored by NeoClassical economists. Eventually, these thoughts construct a framework providing a rationale for regional clusters.

Growth Theories, Neo-Classical approaches: The earliest economic growth models, i.e. those created by Swan and Solow, represent economic growth by an aggregate production function where capital and labour accumulation are the determinants of growth. It is factor accumulation that matters in these models (Aghion et al., 1998). All the models assume diminishing returns to both capital and labour. In the long run, there is no growth possible expect for growth induced by technological change. This technological change is however not incorporated into the model, but rather perceived as something that occurs outside of the scope of economics. In Harrod-Domar's growth models, capital accumulation matters most for economic growth. Saving and capital accumulation by the public or by the state could be used as the key ingredient to economic growth. Technology came upon the industrial sectors like manna from heaven and, although technology gave certain advantages to growth, these are regarded as exogenous to the economic processes (Shaw, 1992). The equilibrium growth rate in the model is when economic growth measured in output is equal to the marginal propensity to save and the capital-output ratio together. New Economic Growth theories oppose the view of diminishing returns to capital and labour and an eventual steady state of economic well being. The most important factors for economic growth in the New Growth theory are not so much labour and capital, but rather the efficient and effective use of these factors. Furthermore, technology development is no longer considered to be exogenous to the economic model. Rather than being influenced by technology, the economic actors are seen as shaping the technological development. The most important contributors to endogenous growth theories are Lucas, Aghion and Howitt and Grossman and Helpman (Kemfer, 2002).

The Institutional Environment and New Growth Theories: The institutional environment comprises all formal and informal rules that delineate the room to manoeuvre for economic actors. Davis and North (1970) define the institutional environment as: "A set of fundamental political, social and legal ground rules that govern economic and political activity". In this vision the institutional environment is not something fixed but is a situation that develops and changes over time. "The institutional environment contains taken-for-granted social and cultural meaning systems or norms that define social 
reality" (Handelman and Arnold, 1999). According to North et al. (1976), efficient economic organization is the key to growth.

According to Porter, competitiveness and the resulting growth are the consequences of private sector activities. The diamond figure represents the importance of embeddedness of these private economic activities in their economic environment. The economic environment of business activities is created by interplay of relations with associated industries, the demand side of the firm, the inputs needed for production, and the appropriate context for production that improves business competitiveness. The importance of the government is the impact a government can have on the four conditions for a competitive private sector.

Observing regional clusters: Geographical concentration of industries is by no means a new and revolutionary concept in economic geography. Economic geography evolves around the questions: what economic activities are located where and why are they located there? Co-location of industries, or industries residing in a geographically concentrated area, was already observed. Marshal observed the co-location of industries into industrial zones in England (Martin and Sunley, 2001). The concentration of these industries in so-called industrial districts was, according to Marshall, rather based on knowledge and knowledge spillovers, the relationship between the industries, and the supporting institutions (Andersen, 1996). "The mysteries of the trade become no mysteries; but are as in the air" (Andersen, 1996). Von Thünen, Weber, Christaller and Lösch were the first and most important economic geographers that determined location decisions of economic activities with the help of models. Perroux noticed that economic growth was not a fluent process and that different regions experienced different economic growth rates. Based on this finding, Perroux concluded that there must exist something which he called growth poles. There are centres of economic growth, whereas other regions lagged behind. (Andersen, 1996) While these theories focus on the input side of the economic process, attention was also given to the output side. Hotelling was the first to recognize the concentration of competitors. The rationale for competitors to co-locate is according to Hotelling found in the demand side of the economy. Instead of locating as far away from the competitor as possible, the location is better chosen close to the competitor. In this way, distance between consumers and sellers is no longer a hindering factor for sales.

Because the approach chosen in this thesis report is based upon dynamic rather than static approaches, i.e. the Institute for Strategy and Competitiveness of Harvard (ISC): Cluster Mapping; and the VINNOVA approach, a clearer picture of the three topics and their relation can be provided. The Shift and Share analysis is dynamic in nature as it measures relative changes in employment overtime. The location quotients as used by the ISC and VINNOVA are static, as they only consider the status quo at a given time. One of the most important shortcomings of these static approaches as presented by the ISC and VINNOVA is that sector scale matters for the detection of regional clusters. Sector scale is important in regional analysis, as small scale sectors can be easily overlooked by statistical analysis (Brown, 2002). When employment indicators are used to find clusters in static approaches, it is very likely that their importance to the regional economy, measured in terms of value added, is underestimated, as employment levels are low. Relative labour extensive sectors, such as biotechnology, have a high value added per worker, and thereby contribute relatively well to per capita value added and economic growth. However, the absolute employment is small.

Dynamic analysis of the growth in employment over a longer period of time can reveal the relative importance of these labour extensive sectors in terms of stronger employment growth. Cluster mapping approaches, such as those of the ISC and VINNOVA, rely on an industry classification standard. The problem is that these standardizations only allow for one classification of the firm. The multitude of possible activities and relations the firm has is therefore underestimated by focusing only on one activity of the firm, rather than looking at all its activities (Cortright, 2006). Because employment development is used in the regional cluster quick scan, the limit of only one classification code will be less constraining. Because employment is measured at sector level, the firm cannot belong to more than one sector. Yet, because this sector scaling includes a wider variety of activities, the constraint is reduced. In order to test the robustness of the findings, it is possible to look at employment development within different sector classifications.

\section{Competitiveness}

Competitiveness is a much sought after concept among policy practitioners and academic researchers alike. The promises of economic development through competitiveness appeals to everyone, but the exact content is very hard to pinpoint. Two very distinct approaches to observe competitiveness can be identified: the ex-ante and ex-post measures of competitiveness. On the one hand, a vast amount of competitiveness rankings is produced where the state of competitiveness is estimated by indicators that enhance competitiveness. This approach is used e.g. by the World Economic Forum (WEF); The Council on Competitiveness and The Competitiveness Program. Ex-post measures are not concerned about the specific indicators that lead to a perceived competitiveness level. These ex-post measures are identifying the revealed effect of competitiveness. If competitiveness is indeed increasing economic development, this should be observed by looking at economic development. The indicators that reveal e.g. ex-post competitiveness are among other added value, GDP per capita, exports and imports.

The construction of competitiveness indices is a complex task involving a vast amount of data. Special about the WEF approach is that quantitative and qualitative data are combined in order to give a precise measurement of 
competitiveness. Together with 'hard' economic statistical data, the WEF issues a survey to business representatives in the countries. Global competitiveness is based on 3 pillars of importance for the competitiveness of nations: Basic requirements, Efficiency enhancers and Innovation factors. The topics included in these indicators are: institutions, physical infrastructure, macro stability, security, basic human capital, advanced human capital, goods markets efficiency, labour market efficiency, financial market efficiency, technological readiness, openness and market size, business sophistication and innovation. The growth competitiveness index is a smaller version of the global competitiveness index, including only those indicators that are perceived to be most directly linked to economic growth performance.

If indeed competitiveness is the capacity for regional or national economies to compete on larger markets, the revealed effects of competitiveness are the results from the sales on those markets. Competitiveness than can be measured by the effects of competitiveness; the increase in added value (Cook and Bredhal, 1991), in sales on nonregional or national markets, i.e. by exports (Feenstra et al., 2006), in the increase in the procurement of inputs, and increase in employment. The last relation, between competitiveness and employment, is less straightforward. However, employment can be used as a substitute for value added as employment data is usually more easily obtained.

\section{Economic growth}

Shift and Share analysis: The Shift and Share analysis has been a commonly used tool among economic geographers for a long time. (Houston, 1967). The effect of changes in employment and the associated competitiveness are calculated to identify the source of competitiveness for regions. From the literature, it becomes clear that the shift and share method is used to find the growth of a region's economic performance by either the structure of the economy or by the region specific components that make the region competitive. The relative components of the shift and share analysis are taken into account, to allow for an interregional comparison of the contribution of the components to competitiveness. The shift and share results used in this research are:

Where:

$$
\begin{aligned}
\mathrm{RAS} & =\frac{\sum_{i} W_{i j t}-\frac{W_{t}}{W_{0}} \sum_{i} W_{i j 0} 0}{W_{i j 0}} \\
\mathrm{RDS} & =\frac{\sum_{i}\left(W_{i j t}-\frac{W_{i t}}{W_{i o}} W_{i j o}\right)}{W_{i j o}}
\end{aligned}
$$

$$
\mathrm{RPS}=\frac{\sum_{i} \frac{W_{i t}}{W_{i o}} W_{i j o}-\sum_{i} \frac{W_{t}}{W_{o}} W_{i j o}}{W_{i j o}}
$$

$\mathrm{W}_{i j 0}=$ Employment sector $_{\mathrm{i}}$ in region ${ }_{\mathrm{j}}$ in year 0

$\mathrm{W}_{i j t}^{i j 0}=$ Employment sector $_{\mathrm{i}}$ in region $_{\mathrm{j}}$ in year $_{\mathrm{t}}$

$\mathrm{W}_{i 0}=$ Employment per sector total economic area in year 0

$\mathrm{W}_{i t}=$ Employment per sector total economic area in year ${ }_{\mathrm{t}}$ (From Heijman, 2002).

Relative shifts: The actual total shift shows the change in employment per sector of the region relative to the change in employment per sector on the national level. The relative actual shift is measured by taking the total economy growth factor in employment and relating this to the employment development of the region. This shows whether the region has grown faster or slower in employment compared to the total economy. The relative actual shift is composed of two components: the structural component shift and the region specific shift.

The structural component of the Shift and Share analysis, also called the relative proportionality shift, explains how the industrial structure of the regional or national economy contributes to overall employment growth performance. It indicates the growth of employment in the region, relative to the development in employment on the national level, to estimate the contribution of fast growing industries to the regional economic development. A negative industry mix component suggests the county has employment concentrated in sectors which are growing more slowly than the overall national economy. This structural shift tells us something about the competitiveness of the region, as derived from the type of economic activities represented there. A fast growing sector that is relatively well represented in the region increases regional development.

The region specific component, also called the relative differential shift, describes how firms in the country or region perform relative to national averages for firms in those same industries. This relative differential shift is also known as a region's measurement of competitiveness. To calculate the competitive share component, base year employment in each local industrial sector is multiplied by the margin between the local sector growth rate and the national average growth rate for that sector. If this shift is positive, it means that the region has attracted relatively more activity in the sector than the national economy. If this growth is negative, the region has not done well in attracting economic activity. This relative differential shift is the component of competitiveness that indicates the regionally specific elements that contribute to its competitiveness. If the relative differential shift is positive, there is something pulling economic activity to that specific location. Without saying anything about the specific indicators that pull the economic activity, it is clear there are positive indicators contributing to regional economic development. 
Employment and economic growth: Although employment development is a much used indicator for Shift and Share development, it may not be the best indicator to represent economic growth. Growth is associated with increased productivity resulting in increased income. Added value, regional exports and market shares (Houston, 1967; Esteban, 2000) provide useful information on the position of the regional economy on larger markets. In this study, the Shift and Share method is applied to employment data because of the availability of reliable data in timeseries for many regions. The directions employment development take, as represented by Shift and Share analysis in relation to competitiveness, are verified by the direction of the relation between competitiveness of countries and the GDP per capita in purchasing power parities in both a static and dynamic approach. It is clear that the direction of the relative proportionality shift in employment on the national level is the same as the direction of the growth in GDP per capita.

\section{The cluster lifecycle, competitiveness and the Shift and Share pattern}

Practical applications: Policy practitioners commonly use and acknowledge the idea of regional clusters being subjected to a so-called 'cluster lifecycle'. (Solvell et al, 2003; Cortright, 2006a). Regional clustering is a dynamic process which occurs over time, where a cluster goes through different phases of development from embryonic to growth to maturation and eventually to a state of declining strength. Reviewing the Italian experience with industry clusters, Bianchi, Miller, and Bertini divide clusters into three broad groups: embryonic, consolidated, and mature. Because of continual changes in markets, competition, and technology, clusters tend to evolve continually, with some clusters ebbing or dying even as new ones form and grow (Cortright, 2006a). In this study, the four stages approach was chosen, following among others Cassidy et al. (2005) and the Cluster Policy White book (2004).

Academic applications: An upsurge in interest for the cluster lifecycle also occurred in science. The first lifecycle to be considered is the product lifecycle (Levitt, 1956). Sales of products are perceived to be low in the initial introduction phase, followed by rapid increase, declining increase and finally decrease of sales. If products are experiencing periods of rapid sales increases, following by a slowdown and eventual decrease in sales, the industries involved are influenced by this product lifecycle in terms of output and sales revenue. If regional concentration of industries around certain product occurs, the regional economy is experiencing the same stages of boom and decline. (Rees, 1979)

The notion of the industrial lifecycle as an important new concept of innovation was first made by Klepper, as he states that "There is accumulating evidence supporting the idea of a 'prototypical' industry lifecycle" (Audretsch et al., 1996).
The industry lifecycle is most commonly considered in terms of the quantity of firms involved in production. In the initial phase of a newly introduced product, the number of independent producers tends to be large and increase. Over time, a 'shake out' effect occurs, where many new firms cease production. The conclusion is that clustering of economic activities is influenced by innovation subjected to industry lifecycles (Klepper, 1992). Brenner (2000) obtains the same results on the firm population and four stages of the industry lifecycle. Regional clustering is influenced by the industry lifecycle, as clustering, or regional concentrations of entering businesses is strong at the beginning of the industrial lifecycle, and at first increasing but later declining again. Dalum et al. (2002) conclude that technological lifecycles are greatly influencing the existence of regional clusters. "New 'disruptive' technologies may initiate the emergence of new regional industrial clusters and/or create new opportunities for further development of existing ones. However, they may also result in stagnation and decline of the latter". In the light of technological innovation, the different lifecycles seem to provide a more dynamic approach to regional clusters. A cluster often passes through different lifecycles, and it is the cluster's capacity to withstand technological change that determines the evolution of the cluster.

The cluster life cycle and employment development: In this report, the cluster lifecycle approach is the foundation for the regional cluster quick scan. The importance of the clustered sector in the regional economy should be observable through an increase in the number of entrances of new companies, as Audretsch (1996) observes. It is therefore hypothesised that employment is also positively associated with the different phases of the cluster lifecycle. In the initial phases of cluster development, when there are increasing but later declining numbers of new entering firms in the regional economy, this should be made visible by looking at the development of employment levels in the region.

\section{Results}

Cluster strength and Competitiveness: National level: The first relation is the link between the state of cluster development on the one hand, and the competitiveness of the economy on the other hand. Quantitative analysis (Table 1) shows a positive correlation coefficient of 0.836 with a significance of the 0.000 level between the strength of clustering in national economies and the global competitiveness ranking of these countries. The growth competitiveness ranking, a less complicated version of the global competitiveness ranking, gives a correlation coefficient of 0.752 with a significance of the 0.000 level. The more competitive a nation, the more likely it is there is stronger clustering of economic activities.

Table 2 provides the results of the regression analysis as performed in this study. The estimated directions and strengths of the relationships are all significant and strong. 
Table 1: Correlation between the state of cluster development ranking and the global competitivenss ranking on the national level

\begin{tabular}{|l|l|c|c}
\hline & & \multicolumn{2}{|c}{ Growth Competitiveness } \\
ranking & index \\
\hline State of cluster development & Pearson Correlation & $0.752(* *)$ & $0.836(* *)$ \\
\hline & Significance (2-tailed) & 0.000 & 0.000 \\
\hline & Number of observations & 58 & 58 \\
\hline
\end{tabular}

** Correlation is significant at the 0.01 level (2-tailed).

Table 2: Regression analysis of the state of cluster development ranking $\left(Y_{1}\right)$ and the competitiveness rankings on the national level

\begin{tabular}{|c|c|c|c|c}
\hline$Y_{1}=\alpha+\beta X_{1}, \quad Y_{1}=\alpha+\beta X_{2}$ & $\alpha$ & $\beta$ & Significance & $\mathrm{R}^{2}$ (adj.) \\
\hline Global competitiveness rank $\left(X_{1}\right)$ & 7.424 & 0.686 & $\alpha 0.002$ & 0.69 \\
& $(3.169)$ & $(11.384)$ & $\beta 0.000$ & \\
\hline Growth competitiveness rank $\left(X_{2}\right)$ & 9.945 & 0.606 & $\alpha 0.001$ & 0.57 \\
& $(3.568)$ & $(8.528)$ & $\beta 0.000$ & \\
\hline
\end{tabular}

Table 3: Correlation between the competitivenss ranks and the Shift and Share analysis national level data

\begin{tabular}{|l|l|c|c|c|}
\hline & Correlations & RDS & RPS & RAS \\
\hline \multirow{2}{*}{$\begin{array}{l}\text { Global } \\
\text { Competitiveness }\end{array}$} & Pearson Correlation & -0.106 & $-0.747(* *)$ & -0.219 \\
\cline { 2 - 5 } & Significance (2-tailed) & 0.630 & 0.000 & 0.316 \\
\cline { 2 - 5 } & Number of observations & 23 & 23 & 23 \\
\hline \multirow{2}{*}{$\begin{array}{l}\text { Growth } \\
\text { Competitiveness }\end{array}$} & Pearson Correlation & -0.057 & $-0.626(* *)$ & -0.153 \\
\cline { 2 - 5 } & Significance (2-tailed) & 0.797 & 0.001 & 0.484 \\
\cline { 2 - 5 } & Number of observations & 23 & 23 & 23 \\
\hline
\end{tabular}

RDS=Relative differential shift, RPS=Relative proportionality shift, RAS=Relative actual shift, ${ }^{* *}$ Correlation is significant at the 0.01 level (2-tailed).

Table 4: Regression analysis of the global competitiveness ranking $\left(Y_{2}\right)$ and growth competitiveness ranking $\left(Y_{3}\right)$ and the national Relative Proportionality Shift $\left(X_{3}\right)$

\begin{tabular}{|l|l|l|l|l|}
\hline$Y_{2}=\alpha+\beta X_{3}, \quad Y_{3}=\alpha+\beta X_{3}$ & $\alpha$ & $\beta$ & significance & $\mathrm{R}^{2}$ (adj.) \\
\hline Global competitiveness rank $\left(Y_{2}\right)$ & 22.184 & -641.309 & $\alpha 0.000$ & 0.54 \\
& $(8.361)$ & $(-5.141)$ & $\beta 0.000$ & \\
\hline Growth competitiveness rank $\left(Y_{3}\right)$ & 22.037 & -433.982 & $\alpha 0.000$ & 0.36 \\
& $(8.771)$ & $(-3.674)$ & $\beta 0.001$ & \\
\hline
\end{tabular}

Table 5: Correlation between NUTS-1 level competitiveness ranks and the results of the Shift and Share analysis (full data set) and correlations between the NUTS-1 level competitiveness and the results from the Shift and Share analysis (with outlier analysis)

\begin{tabular}{|l|c|c|c|c|}
\hline & \multicolumn{2}{|c|}{ Huggins Rank } & \multicolumn{2}{c|}{ Huggins Score } \\
\hline & $\begin{array}{c}\text { Pearson } \\
\text { Correlation }\end{array}$ & $\begin{array}{c}\text { Significance } \\
(2 \text {-tailed) }\end{array}$ & $\begin{array}{c}\text { Pearson } \\
\text { Correlation }\end{array}$ & $\begin{array}{c}\text { Significance } \\
\text { (2-tailed) }\end{array}$ \\
\hline RAS (N=51) & $0.474(* *)$ & 0.000 & $-0.451(* *)$ & 0.001 \\
\hline RDS (N=51) & $0.551(* *)$ & 0.000 & $-0.538(* *)$ & 0.000 \\
\hline RPS (N=51) & $-0.572(* *)$ & 0.000 & $0.622(* *)$ & 0.000 \\
\hline RAS (N=44) & $0.628(* *)$ & 0.000 & $-0.578(* *)$ & 0.000 \\
\hline RDS (N=44) & $0.697(* *)$ & 0.000 & $-0.662(* *)$ & 0.000 \\
\hline RPS (N=44) & $-0.567(* *)$ & 0.000 & $0.618(* *)$ & 0.000 \\
\hline
\end{tabular}

** Correlation is significant at the 0.01 level (2-tailed).
The correlation analysis and the regression analysis both indicate that the state of cluster development is closely and significantly interrelated with the level of competitiveness of nations. In more competitive nations, it is more likely that strong clustering of economic activities can be observed.

Competitiveness and the Shift and Share analysis: national level: The second relation is the relation between competitiveness on the one hand, and the relative Shift and Share analysis on the other hand (Table 3). On the national level, it is the relative proportionality shift that indicates competitiveness with a correlation coefficient of -0.747 and -0.626 with a significance of 0.000 for the global competitiveness rank and the growth competitiveness rank, respectively. The strongly negative relation indicates that the stronger the relative proportionality shift, the stronger the structure of the economy and the more competitive the country is.

On the basis of the national level analysis, it is clear that the relative proportionality shift yields the only strongly significant results for further analysis. The relative actual and the relative differential shift seem to have no important connection. Table 4 shows the relation between the relative proportionality shift and the global competitiveness rankings.

One remark that has to be made in this case is that the number of observations, 23 countries that were used is rather small for reliable statistical analysis. It is used in this report merely as a first indicator rather than a source of strong conclusions.

Competitiveness and the Shift and Share analysis: regional level

Finally, the relation between the Shift and Share analysis and the regional competitiveness index was estimated. This allows for a much more detailed analysis for regional development and allows for more cases to be entered. On the regional level, competitiveness is significantly determined by all three shifts: the strong and negative relative proportionality shift, and the strong 
and positive relative differential and relative actual shift with correlation coefficients of $-0.572 ; 0.551$ and 0.474 , all significant to the 0.000 level (see Table 5). The same correlation analysis was performed with the more expanded analysis. This more expanded analysis was performed to test for the disturbance of some divergent observations in the dataset. Here, the Relative proportionality shift scores -0.567 and the relative differential- and the relative actual shift score 0.697 and 0.628 , respectively, all significant to the 0.000 level.

Table 6 shows the relations between the regional competitiveness level and the relative actual shift. Table 7 shows the results from the regional competitiveness related to the relative differential and relative proportionality shift. Figure 2 shows the directions of the relations between the relative differential and relative proportionality shift. From the analysis, it is clear that the two shifts are indeed strongly and significantly related to the competitiveness of the region.

Competitiveness and GDP per capita: National level: Employment development as represented by the Shift and Share analysis correlates with competitiveness significantly and negatively on the regional level. More competitive regions experience less growth in employment than less competitive regions. Because these results were not expected beforehand, as it was expected that stronger regions in terms of competitiveness will have more economic growth, the results were checked for consistency with GDP per capita growth in the same countries with an addition of 7 countries, in the same period (1999-2004).

Table 8 presents the correlations between the global and growth competitiveness indices the GDP per capita, both in a static and a dynamic picture. The correlations estimated are not as strong as the Shift and Share results are in relation to competitiveness, but the picture they represent is still concise. Competitiveness and
Table 6: Regression analysis of the Regional Competitiveness Rank $\left(Y_{4}\right)$ and Regional Competitiveness Score $\left(Y_{5}\right)$ and the Relative Actual Shift $\left(X_{4}\right)$

\begin{tabular}{|l|l|l|l|l|}
\hline \multicolumn{4}{|l|}{$Y_{4}=\alpha+\beta X_{4}, \quad Y_{5}=\alpha+\beta X_{4}$} \\
\hline RAS & $\alpha$ & $\beta$ & significance & $\mathrm{R}^{2}$ (adj.) \\
\hline Regional Competitiveness Rank & 43.913 & 266.737 & $\alpha 0.000$ & 0.39 \\
& $(14.549)$ & $(5.224)$ & $\beta 0.000$ & \\
\hline Regional Competitiveness Score & 102.605 & -516.413 & $\alpha 0.000$ & 0.32 \\
& $(15.431)$ & $(-4.591)$ & $\beta 0.000$ & \\
\end{tabular}

Table 7: Regression analysis of the Regional Competitiveness Rank $\left(Y_{4}\right)$ and Regional Competitiveness Score $\left(Y_{5}\right)$ and the Relative Differential Shift $\left(X_{5}\right)$ and the Relative Proportionality Shift $\left(X_{6}\right)$

\begin{tabular}{|l|c|c|c|c|c|}
\hline \multicolumn{2}{|c|}{$Y_{4}=\alpha+\beta X_{5}, \quad Y_{5}=\alpha+\beta X_{6}$} \\
\hline RDS; RPS & $\alpha$ & $\beta$ & $\gamma$ & Significance & $\mathrm{R}^{2}$ (adj.) \\
\hline Regional & 46.275 & 217.759 & -601.027 & $\alpha 0.000$ & 0.54 \\
Competitiveness Rank & $(17.438)$ & $(4.793)$ & $(-2.726)$ & $\beta 0.000$ & \\
& & & & $\gamma 0.009$ & \\
\hline Regional & 96.844 & -396.977 & 1599.692 & $\alpha 0.000$ & 0.54 \\
Competitiveness Score & $(17.352)$ & $(-4.154)$ & $(3.450)$ & $\beta 0.000$ & \\
& & & & $\gamma 0.001$ & \\
\hline
\end{tabular}

Table 8: Correlation between the GDP per capita in a static and dynamic representation and the competitiveness ranks national level data.

\begin{tabular}{l|l|c|c|c|c}
\hline & & \multicolumn{2}{|c|}{$\begin{array}{c}\text { Global Competitiveness } \\
\text { rank score }\end{array}$} & \multicolumn{2}{c}{$\begin{array}{c}\text { Growth Competitiveness } \\
\text { rank score }\end{array}$} \\
\hline GDP 2004 & $\begin{array}{l}\text { Pearson } \\
\text { Correlation }\end{array}$ & $\begin{array}{c}-0.685 \\
(* *)\end{array}$ & $\begin{array}{c}0.688 \\
(* *)\end{array}$ & $\begin{array}{c}-0.674 \\
(* *)\end{array}$ & $\begin{array}{c}0.668 \\
(* *)\end{array}$ \\
\hline in ppp & $\begin{array}{l}\text { Significance } \\
(2-t a i l e d)\end{array}$ & .000 & .000 & .000 & .000 \\
\hline$\%$ change & $\begin{array}{l}\text { Pearson } \\
\text { Correlation }\end{array}$ & 0.333 & -0.355 & $\begin{array}{c}0.365 \\
(*)\end{array}$ & $\begin{array}{c}-0.374 \\
(*)\end{array}$ \\
\hline $\begin{array}{l}\text { in GDP per } \\
\text { capita }\end{array}$ & $\begin{array}{l}\text { Significance } \\
\text { (2-tailed) }\end{array}$ & 0.072 & 0.055 & 0.047 & 0.042 \\
\hline
\end{tabular}

* Correlation is significant at the 0.05 level (2-tailed).

** Correlation is significant at the 0.01 level (2-tailed). $\mathrm{N}=30$ for all correlations.
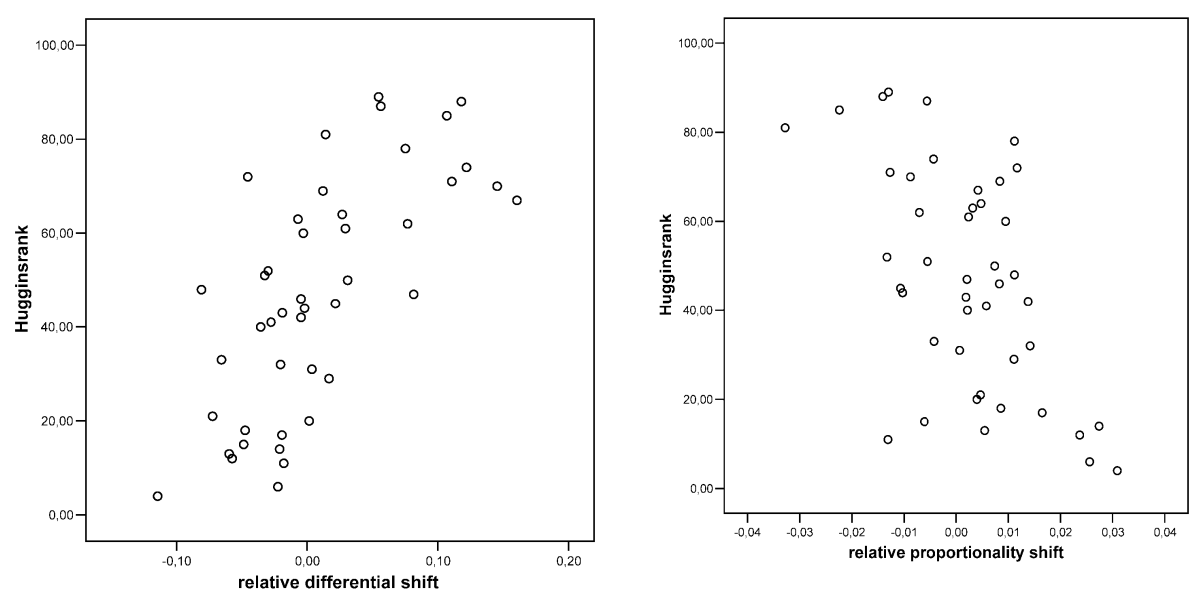

Figure 2: Scatter diagram of Huggins rank and relative differential shift (left panel) and relative proportionality shift (right panel) 
GDP per capita are related in a positive way when the level of GDP per capita in 2004 is taken into account. The global competitiveness rank and the growth competitiveness rank give a correlation coefficient of -0.685 and -0.674 , respectively, at the significance level of 0.000 . The stronger the competitiveness of the country is, the higher the GDP per capita. A more dynamic approach where the GDP per capita in purchasing power parity growth is taken in to account, does give a less concise yet important result. The weaker but very significant relation between the growth competitiveness index and the GDP per capita growth over a five year period shows that GDP per capita growth and competitiveness are negatively correlated with a correlation coefficient of -0.374 and a significance of 0.042 . GDP growth per capita seems negatively correlated to competitiveness, indicating that more competitive countries experience slower GDP per capita growth.

The same results have been identified by the ETLA institute. The ETLA conclusion is that "Experience has shown that a strong ranking in competitiveness indices does not guarantee favourable economic growth in subsequent years (Vartia and Nikinmaa, 2006)". And: "An even stronger positive association is found with backwardness. It is easier for economies to grow fast when they are catching up from a long way behind. But it would be perverse to include being backward as a competitive strategy (Hawkins, 2006)." From these results, on the relation between GDP per capita in PPP and the employment development on the one hand, and competitiveness on the other hand, it can be concluded that for both GDP and employment, the growth rates slow down with increasing competitiveness.

\section{Designing the regional cluster quick scan}

Shift and Share analysis and the cluster lifecycle: In the previous section, the estimation of the relations between the strength of clusters, competitiveness and employment development were estimated. Statistical data analysis shows that there are indeed significant and strong relations between the concepts. Stronger clusters do indeed have a higher competitiveness level. Higher levels of competitiveness do correlate to a faster employment development in the proportionality shift and slower employment development in the differential shift on the regional level analysis. Based on these statistical analyses and the theory on the cluster lifecycle (see also section 2), the final step in this empirical theoretical part of the research is taken. Based on the relations between cluster development and competitiveness; and competitiveness and the results of the Shift and Share analysis on employment development of regions, the regional cluster quick scan is developed. In the regional cluster quick scan, the employment development as represented by the Shift and Share results are representing unique patterns of cluster development.
The objective is to identify the unique pattern of Shift and Share analysis in every phase of the cluster as it develops according to the cluster lifecycle. Although the ideal method is to identify the different Shift and Share patterns for one cluster over time, this approach was not chosen due to data availability issues. There is no time series data on the development of regional clusters. The unique patterns of Shift and Share analysis and the associated levels of competitiveness of one cluster are identified by a crosssection of regions: by comparing many regions with different levels of competitiveness and different results on the Shift and Share analysis, it is possible to determine the cluster development of a region based on the cluster lifecycle. It is hypothesised that clusters grow through different phases of development and decline, and that these different phases of cluster development can be identified through Shift and Share analysis.

Descriptive statistics of the Shift and Share analysis and the cluster lifecycle: For a more detailed overview of the scores on the Shift and Share analysis of the $25 \%$ best performing regions, the most competitive regions were compared to the $25 \%$ of those regions that scored lowest on the competitiveness rank. Table 9 presents the Shift and Share pattern for these 11 most competitive and the 11 least competitive regions. The 11 best performing regions all have a relative differential shift of at least 0 , but 10 out of the 11 score below 0 . The relative proportionality shift is mostly positive or 0 ; only in two cases the relative proportionally shift is negative. Although the number of observations is rather small, these results are inline with the correlation and regression analyses as presented in the previous section.

Second, a more precise estimation of the boundaries of the different stages of the Shift and Share analysis on the cluster lifecycle is given by an analysis of the percentiles in the data set. Although these observations and the boundaries are dependent on the data set, they do allow for a first analysis of the possibility of unique Shift and Share patterns for the cluster lifecycle phases.

The relative differential shift shows the highest spread in the observations, ranging from a score of -0.11 up to +0.16 , and also shows the lowest correlation to the competitiveness rankings. The relative proportionality shift shows a much more concise picture: the extreme boundaries of the relative proportionality range from -0.03 to +0.03 . The relative proportionality shift therefore shows a more consistent picture. 12 shifts are $0.00 ; 13$ shifts are -0.01 and 12 shifts are +0.01 . Only 7 shifts deviate more from 0 than an absolute

Table 9: Comparison of the $25 \%$ most competitive and the $25 \%$ least competitive regions and the results from the Shift and Share analysis

\begin{tabular}{|l|l|l|}
\hline & $25 \%$ best performers & $25 \%$ worst performers \\
\hline $\begin{array}{l}\text { Relative differential } \\
\text { shift }\end{array}$ & $10 / 11$ negative, $1 / 11$ zero & $10 / 11$ positive, 1/11 negative \\
\hline $\begin{array}{l}\text { Relative } \\
\text { proportionality shift }\end{array}$ & $\begin{array}{l}7 / 11 \text { positive, } 2 / 11 \text { negative, } \\
2 \text { zero }\end{array}$ & $\begin{array}{l}7 / 11 \text { negative, } 3 / 11 \text { positive, } \\
1 \text { zero }\end{array}$ \\
\hline Relative actual shift & $\begin{array}{l}7 / 11 \text { negative, } 2 / 11 \text { positive, } \\
2 \text { zero }\end{array}$ & $9 / 11$ negative, $2 / 11$ positive \\
\hline
\end{tabular}


value of 0.01 . Therefore, the average score of the positive proportionality shifts is only 0.02 and the average score when the proportionality shift is negative is -0.01 . In those rare cases where the proportionality shift is either stronger positive and stronger negative, the distribution of these stronger shifts is as expected. The two cases where the proportionality shift is smaller than -0.01 are both in the $25 \%$ worst performing regions and reversely, the strongest positive proportionality shifts are also found in the top $25 \%$ regions. The boundaries of the percentiles, as can be observed given the available data set, are presented in Table 10. The boundaries of the different phases of the cluster lifecycle are calculated by the observed percentile scores of the regions in the data set.

The regional cluster quick scan: The analytical model that represents the cluster development in regions is represented by figure 3 . The slope of the curve shows the relative changes in employment over time when the cluster develops. Table 11 shows the direction and the strength of these changes in employment.

In the initial stages of cluster development, when the cluster is still weak in competitiveness, the relative differential shift is strong and positive. The relative proportionality shift shows the reverse picture. The structure of the economy is weak and employment development in region as a result of this structure is lagging behind in comparison to the larger economic unit. As the cluster develops and the competitiveness increases, the relative differential shift is decreasing, indicating slower employment development in the region. In the developing phase of the cluster lifecycle the employment development is however still relatively large. The relative proportionality shift is still weak, but the structure is gaining importance, represented by a still negative, but less strong relative proportionality shift in the developing phase of the cluster lifecycle. When the cluster is maturing the shifts change in direction. In the mature and declining phase of cluster development the relative differential shift becomes negative, with an increasing strength. Employment development in the region will fall behind the employment development of the larger unit of comparison. However, the structure of the regional economy as represented by the relative proportionality shift will be positive with increasing strength. The relative actual shift, indicating the relative total employment development of the region in comparison to the larger economic unit is not taken into account in the regional cluster quick scan because of the high multi colinearity between the relative actual shift and the relative differential shift.
Table 10: The boundaries of the cluster lifecycle as given by the unique pattern of the Shift and Share analysis (based on the percentile scores of the regions in the data set)

\begin{tabular}{|l|c|c|c|c|}
\hline & $\begin{array}{c}\text { Embryonic } \\
\text { phase }\end{array}$ & $\begin{array}{c}\text { Developing } \\
\text { phase }\end{array}$ & $\begin{array}{c}\text { Mature } \\
\text { phase }\end{array}$ & $\begin{array}{c}\text { Declining } \\
\text { phase }\end{array}$ \\
\hline Proportionality & $<-0.01$ & $>-0.01$, & $>0.00$, & $>0.01$ \\
shift & & $<0.00$ & $<0.01$ & \\
\hline Differential shift & $>0.03$ & $<0.03$, & $<0.00$, & $>-0.03$ \\
& & $>0.00$ & $>-0.03$ & \\
\hline
\end{tabular}

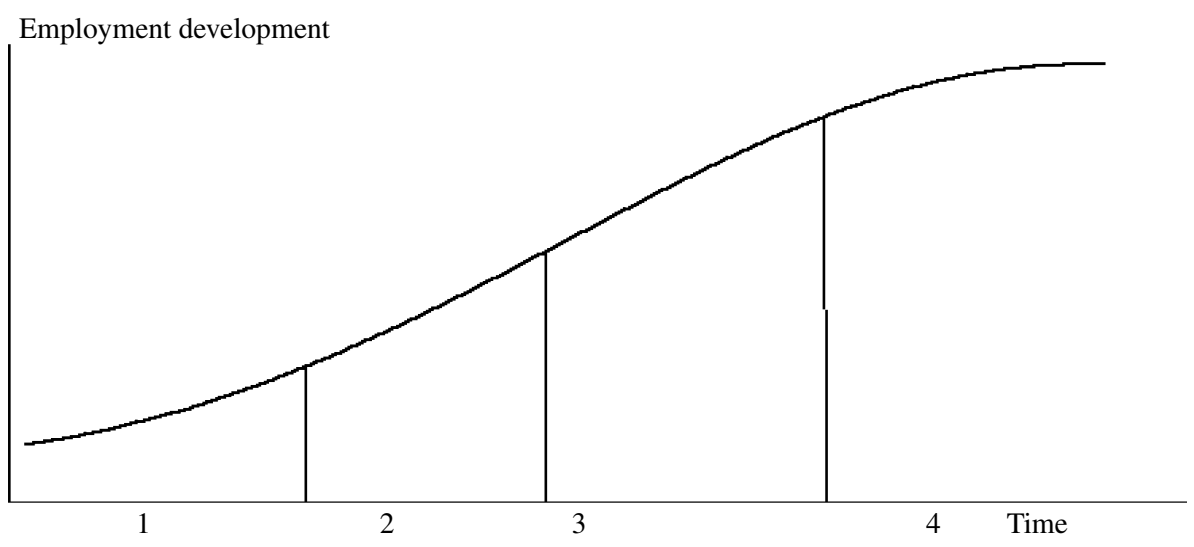

Figure 3: The four phases of the cluster lifecycle and employment development

Table 11: The boundaries of the cluster lifecycle as given by the unique pattern of the Shift and Share analysis (less dependent on the data set as used in this research)

\begin{tabular}{|l|c|c|c|c|}
\hline & $\begin{array}{c}\text { Embryonic } \\
\text { Phase }\end{array}$ & $\begin{array}{c}\text { Developing } \\
\text { Phase }\end{array}$ & $\begin{array}{c}\text { Mature } \\
\text { Phase }\end{array}$ & $\begin{array}{c}\text { Declining } \\
\text { Phase }\end{array}$ \\
\hline Relative Proportionality Shift & $<0$ & $<0$ & $>0$ & $>0$ \\
\hline Relative Differential Shift & $>0$ & $>0$ & $<0$ & $<0$ \\
\hline
\end{tabular}

\section{Conclusions}

The regional cluster quick scan is a time and cost efficient and objective tool for policy practitioners and academic researchers to screen their region of interest for potential clusters. Based on quantitative data analysis the relations between clusters, competitiveness and employment development are established and used to design the regional cluster quick scan.

Because clusters and competitiveness go hand in hand, it is possible to determine the presence of potential regional clusters by observing regional competitiveness. More competitive regions are more likely to have clustered economic activities in multiple sectors. Competitiveness of the European regions is measured at NUTS-1 level only; the preferred scale of measurement may be much smaller. This is why employment development of the region in relation to European average employment development is taken as a determinant of competitiveness through Shift and Share analysis. In general, more competitive regions experience slower employment development in comparison to less competitive 
regions; in other words, less competitive regions have a higher employment growth than more competitive regions. The composition of this growth in employment as analysed by applying the Shift and Share analysis is even more interesting. More competitive regions have a slower overall employment development, caused by the negative relative differential shift. Yet, this negative relative differential shift is moderated by a positive relative proportionality shift. The structure of the economy contributes positively to competitiveness; the region specific elements are impacting competitiveness negatively.

Second, because clusters in different phases of the cluster lifecycle and with different levels of competitiveness show distinguished employment development patterns represented by the Shift and Share analysis, the phase of cluster development can be determined. Generally speaking, clusters in the early stages of the cluster lifecycle are fast developing in the relative differential shift, the shift indicating the region specific elements for growth, whereas in these early phases growth caused by the structure of the economy, as represented by the relative proportionality shift is still slow. In more mature and even declining clusters, these patterns of the relative differential and relative proportionality shift change. In the final stages of the cluster lifecycle, the structure of the economy is stronger and contributing positively to employment development. However, the region specific elements contribute negatively to employment development.

Finally, because the employment development per economic sector is taken into account, the sectors in these potential clusters can be identified. Those sectors that experienced relative high employment development in a given time period are considered to be the competitive sectors. These are the sectors that performed well in comparison to the larger economic unit to which employment growth is compared.

Interviews with experts on regional cluster development, on the role of development agencies and governments in the cluster development process, yield interesting suggestions for policy towards the development of strong regional clusters. Conclusions of the analysis of the interviews suggest that cluster formation cannot be enforced by government agencies. Clusters arise and thrive because of private sectors interest and private sector involvement. Government policies are however important for facilitating the initial stages of clustering and by providing the appropriate business climate for clusters to arise and thrive. In different phases of the cluster lifecycle, different facilitating activities can be performed by the non-private sector to enhance and improve cluster development and to keep the clusters strong and competitive.

The regional cluster quick scan, as designed in this study, shows potential regional clusters based on employment development in certain sectors per region. Still, the fact that clusters are by definition geographically concentrated does not necessarily mean that clusters are bounded by these regional borders: it is possible that clusters cross regional borders. The question that remains unanswered is whether or not regional clusters that cross these borders can be detected using this approach. For clusters that do affect the regional economy greatly, the multi-regional problem is not applicable, but the method does underestimate the importance of clusters that cross regional boundaries and that do not therefore affect employment development in one region in particular.

Furthermore, there is the issue of multiple clusters in one region. A region can experience multiple cluster development as more industries tend to cluster, but these industries are not related in the same network. These clusters are not necessarily in the same stages of cluster development, some may be still in the initial phases of cluster development, whereas others may be in the final stages of development. Our research does not clarify how these different clusters and their effects on employment development, as represented by the Shift and Share analysis, work out on the regional cluster quick scan.

Further research is needed into the exact boundaries of the cluster lifecycle and employment development as indicated by the Shift and Share analysis. A larger data set can give more reliable boundaries to the Shift and Share results and the cluster lifecycle. Furthermore, time series data on cluster development in competitiveness and employment development can further justify the hypothesis that clusters go through certain phases of cluster lifecycles and that these phases can be quantitatively known.

The data used for the Shift and Share analysis, the employment data in countries, regions and the European Union as a whole, is chosen because of the availability and reliability of the data. It would however be adding to the credibility of the conclusions drawn in this research if the employment data were not taken into account, but the added value of the different sectors would be taken instead. Added value data offers a more insightful approach to the Shift and Share results and competitiveness because added value is directly linked to economic growth, whereas employment development is a proxy for this growth. The immediate danger of taken employment data instead of added value data is the underestimation of automation of economic sectors. In these cases, employment development may be slow, but the added value directly contributing growth may proof to be important.

\section{References}

Aghion P. and P.W. Howitt (1998): Endogenous Growth Theory. books.google.com.

Andersson T., S. Schwaag-Serger and J. Sörvik (2004): The cluster policy white book. IKED.

Andersen E.S. (1996): Theories of Localised Resource-Based Growth and Development - from Marshall to New Evolutionary Economics, Aalborg University.

Audretsch D.B. and M.P. Feldman (1996): Innovative Clusters and the industry lifecycle, Review of Industrial Organization, 11, pp. 253-273. 
Brown, R. (2000): Cluster Dynamics in Theory and Practice with application to Scotland, Regional and Industrial Policy Research Paper, European Policies Research Centre 38

Cassidy, E., C. Davis, D. Arthurs, and D. Wolfe (2005): Measuring the National Research Council's Technology Cluster Initiatives, presented at CRIC Cluster Conference on Beyond Cluster - Current Practices \& Future Strategies, Ballarat, June 30-July 1, 2005.

Cook M.L and M.E. Bredhal (1991): Agribusiness competitiveness in the 1990s: discussion, American Journal of Agricultural Economics, 73 (5) pp 1472-1473

Cortright J. (2006a): Making sense of clusters: regional competitiveness and economic development, the Brookings institution Metropolitan Policy Program.

Cortright J. (2006): Industry Clusters: Techniques for understanding clusters at www.oregonclusters.org.

Dalum B., C. Ø. R. Pedersen, and G. Villumsen G. (2002): Technological Life Cycles: Regional Clusters Facing Disruption, DRUID Working Paper No 02-10.

Davis L. and D.C. North (1976): Institutional change and American economic growth: A first step towards a theory of institutional innovation, Journal of Economic History, 30 (1), pp. 131-149.

Esteban J. (2000): Regional convergence in Europe and the industry mix: a shift share analysis, Regional science and Urban economics, 30 (3), pp. 353-364.

Feenstra R. C and A. K. Rose (2000): Putting Things in Order: Trade Dynamics and Product Cycles. The Review of Economics and Statistics, 82 (3), pp. 369-382.

Handelman J.M. and S.J. Arnold (1999): The role of market actions with a social dimension: Appeals to the institutional environment, Journal of Marketing, 63 (3), pp. 33-48.

Hawkins J. (2006): The concept of competitiveness, Australian Treasury working paper 022006 at www.treasury.gov.au.

Heijman W.J.M. (2002): Regionale Economie: Van vestigingsplaats naar regionale ontwikkeling. Eburon (in Dutch).
Hillhorst P. and R. Westerlaken (2003): Clusters in de Betuwe: analyse van plantaardige agro-clusters in het rivierengebied. Wageningen University, Msc Thesis.

Houston D.B. (1967): The Shift and Share analysis of regional growth: a critique, Southern Economic Journal, 33 (4), pp. 577-581.

Huggins R. (2004): European Competitiveness Index Robert Huggins Associates.

Kemfer C. (2002): Induced Technological Change in a MultiRegional, Multi-Sectoral Integrated Assessment Model (WIAGEM)", University of Oldenburg, mimeo.

Ketels C. and Ö. Sölvell (2006): Clusters in the ten new member states, from www.competitiveness.org.

Martin R. and P. Sunley P. (2001): Deconstructing clusters: Chaotic Concept or Policy Panacea? Revised Version of a Paper Presented at the Regional Studies Association Conference on Regionalising the Knowledge Economy Submitted to Journal of Economic Geography.

National Competitiveness Council (2001): Annual Competitiveness Report, www.forfas.ie

North D.C. and R.P. Thomas (1976): The rise of the Western world; a new economic history, Cambridge University press.

Porter, M. E. (1990): The Competitive Advantage of Nations, Free Press, New York.

Porter, M. E. (1998): Clusters and the new economics of competition, Harvard Business Review, 76 (6), pp. 77-90.

Shaw G. K. (1992): Policy implications of endogenous growth theory. Economic Journal, 102, pp. 611-621.

Sölvell Ö. , G. Lindqvist and C. Ketels (2003): The cluster initiative green book, from www.ivorytower.se_2003.

Vartia P. and T. Nikinmaa (2004): What do competitiveness comparisons tell us? www.etla.fi.

World Economic Forum (2004): Global competitiveness Report 2004. 